\title{
Plasma hydrogenation of strain-relaxed SiGe/Si heterostructure for layer transfer
}

\author{
Peng Chen and Paul K. Chu ${ }^{\text {a) }}$ \\ Department of Physics and Materials Science, City University of Hong Kong, Tat Chee Avenue, \\ Kowloon, Hong Kong \\ T. Höchbauer and M. Nastasi \\ Los Alamos National Laboratory, Los Alamos, New Mexico, 87545 \\ D. Buca and S. Mantl \\ Institut für Schichten und Grenzflaechen and cni-Center of Nanoelectronic Systems for Information \\ Technology, Forschungszentrum Juelich, D-52425 Juelich, Germany \\ N. David Theodore \\ Advanced Products Research and Development Laboratory, Freescale Semiconductor Incorporated, \\ 2100 East Elliot Road, Tempe, Arizona 85284 \\ T. L. Alford and J. W. Mayer \\ Department of Chemical and Materials Engineering, Arizona State University, Tempe, Arizona 85287 \\ R. Loo and M. Caymax \\ IMEC, Kapeldreef 75, B-3001 Leuven, Belgium
}

M. Cai and S. S. Lau

University of California at San Diego, San Diego, California 92093

(Received 24 June 2004; accepted 22 September 2004)

\begin{abstract}
The use of plasma hydrogenation for relaxed SiGe layer transfer is demonstrated. It is found that the interface of a strain-relaxed $\mathrm{SiGe} / \mathrm{Si}$ heterostructure is effective in trapping $\mathrm{H}$ during plasma hydrogenation. Long microcracks observed at the interface due to the trapping of indiffused $\mathrm{H}$ indicate the distinct possibility of transferring the overlayer using the ion-cutting technique. Our results suggest that interfacial defects induced by the He implantation relaxation process trap the indiffusing $\mathrm{H}$ atoms and lead to interfacial cracks during hydrogenation or upon postannealing at higher temperatures. It is further noted that trapping of $\mathrm{H}$ at the interface is possible only in strain-relaxed structures. Without strain relaxation, $\mathrm{H}$ atoms introduced by plasma hydrogenation get trapped just below the sample surface and form a band of shallow platelets. Without the need for high-dose high-energy ion implantation, our results suggest an effective way for high-quality strain-relaxed SiGe layer transfer. The technique has potential for application in the fabrication of SiGe-on-insulator strained Si epitaxial layer and related structures. (C) 2004 American Institute of Physics. [DOI: 10.1063/1.1824171]
\end{abstract}

SiGe-on-insulator (SGOI) combines the advantages of $\mathrm{SiGe}$ and silicon-on-insulator technologies, such as the reduction of parasitic capacitances, improvement of isolation, and mitigation of short channel effects. ${ }^{1}$ In addition, relaxed $\mathrm{SGOI}$ is a versatile substrate for the fabrication of strained $\mathrm{Si}$ layers, III-V optoelectronic devices, and so on. SGOI structures have been fabricated by separation by implantation of oxygen $^{2}$ as well as by Ge condensation during $\mathrm{SiGe}$ oxidation. ${ }^{3}$ Some groups have attempted to fabricate SGOI using the ion-cutting technology based on high-dose hydrogen ion implantation into relaxed $\mathrm{SiGe} / \mathrm{Si}$ substrates followed by wafer bonding. ${ }^{4,5}$ However, the crystalline quality of the transferred SiGe layer is usually not satisfactory and several processing-related issues have not been solved. ${ }^{6,7}$ Hydrogen ion implantation produces a layer with a broad distribution of damage that will extend to the surface in the case of thin layer transfer. For low ion energies, the damage can be so significant in the surface region that the transferred

\footnotetext{
${ }^{a}$ Author to whom correspondence should be addressed; electronic mail:
} paul.chu@cityu.edu.hk layer is likely to be useless. The purpose of this work is to investigate an alternative approach that replaces the hydrogen ion implantation step with plasma hydrogenation in order to avoid the shortcomings caused by hydrogen implantation. The effects of the He-induced strain relaxation process on the H-trapping mechanism are also examined.

$\mathrm{SiGe} / \mathrm{Si}$ heterostructures consisting of a $210 \mathrm{~nm}$ thick $\mathrm{Si}_{0.79} \mathrm{Ge}_{0.21}$ epitaxial layer on $\langle 100\rangle p$-Si substrate with a resistivity of $1-10 \Omega \mathrm{cm}$ were fabricated by chemical vapor deposition (CVD). A portion of the as-grown sample was implanted with $1.5 \times 10^{16} \mathrm{~cm}^{-2} \mathrm{He}^{+}$at $45 \mathrm{kV}$, and then annealed at $850{ }^{\circ} \mathrm{C}$ for $10 \mathrm{~min}$ in argon to relax the as-grown strained $\mathrm{SiGe} / \mathrm{Si}$ heterostructure. Hydrogenation was conducted in a plasma ion immersion implantation equipment with a radio-frequency plasma source, which offers higher efficiency than a conventional beamline ion implanter and plasma uniformity better than $2 \%$ across the wafer. ${ }^{8,9}$ The sample holder was subjected to a negative bias of several hundred volts and heated to $320-380^{\circ} \mathrm{C}$ during hydrogenation for $1.5 \mathrm{~h}$. It should be pointed out that a much shorter hydrogenation time at the same temperature followed by a 


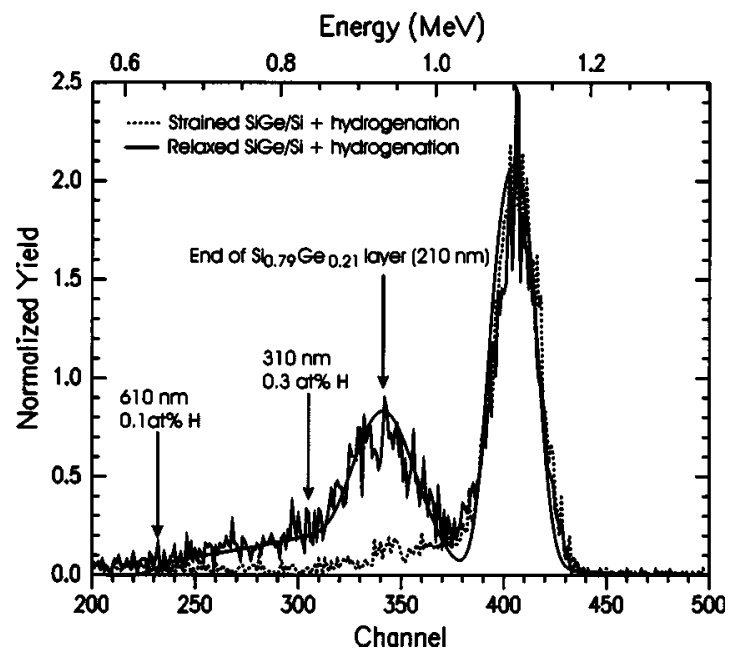

FIG. 1. $3.0 \mathrm{MeV} \mathrm{He}^{+}$ERD spectra acquired from hydrogenated $\mathrm{Si}_{0.79} \mathrm{Ge}_{0.21} / \mathrm{Si}$ heterostructures: (a) CVD as grown; (b) after 1.5 $\times 10^{16} / \mathrm{cm}^{2}, 45 \mathrm{kV} \mathrm{He}{ }^{+}$implantation and postannealing at $850{ }^{\circ} \mathrm{C}$ for $10 \mathrm{~min}$ in Ar. The calculated $\mathrm{H}$ depth distribution from sample (b) is overlaid.

postanneal could also produce surface blistering. An optical microscope with Nomarski lenses was used to check for surface bubble formation at three different sample areas after hydrogenation. Elastic recoil detection (ERD) and crosssectional transmission electron microscopy (XTEM) were also used to characterize the structure of the samples.

Surface blistering study provides a convenient way to obtain insight into the mechanism of hydrogen-induced layer cleavage. After our hydrogenation experiments, both samples with and without He-induced relaxation show surface bubbles. The sample without He implantation has a bubble density of $1.3 \times 10^{7} \mathrm{~cm}^{-2}$ and the average bubble size is $0.6 \mu \mathrm{m}$, whereas the He-implanted sample has a bubble density of $1.6 \times 10^{7} \mathrm{~cm}^{-2}$ and the average bubble size is $1.8 \mu \mathrm{m}$. Our results thus indicate that the samples with He implantation exhibit a higher degree of surface blistering than the ones without $\mathrm{He}$ implantation.

The ERD spectra in Fig. 1 indicate different $\mathrm{H}$ distributions in the hydrogenated samples with and without $\mathrm{He}$ implantation. A small near-surface hydrogen peak is observed in both hydrogenated samples. The peak position matches the expected implantation depth for a few hundred volts hydrogen coming into the surface of the wafer during hydrogenation. Little or no notable hydrogen content and accumulation can be detected within the bulk SiGe sample without $\mathrm{He}$ implantation. However, in the He-relaxed and -hydrogenated sample, $\mathrm{H}$ atoms get trapped at a specific depth below the sample surface, resulting in a significant $\mathrm{H}$ peak deep in the substrate. By using appropriate substrate parameters [210 nm thick $\mathrm{Si}_{0.79} \mathrm{Ge}_{0.21}$ layer on $\mathrm{Si}$, as determined by Rutherford backscattering spectrometry (RBS) (not shown)] for simulation of the ERD spectrum, the hydrogen depth profile is determined and shown in the inset in Fig. 1. The hydrogen depth distribution, which is Gaussian-type, shows a peak at $210 \mathrm{~nm}$, full width at half-maximum of $110 \mathrm{~nm}$, and an integrated dose of $9 \times 10^{15} \mathrm{~cm}^{-2}$. These results reveal that due to the lack of $\mathrm{H}$ trapping sites in the as-grown strained $\mathrm{SiGe} / \mathrm{Si}$ sample, plasma hydrogenation by itself cannot result in accumulation of hydrogen at a specific depth deep in the substrate beyond the near-surface region. Hydrogenation

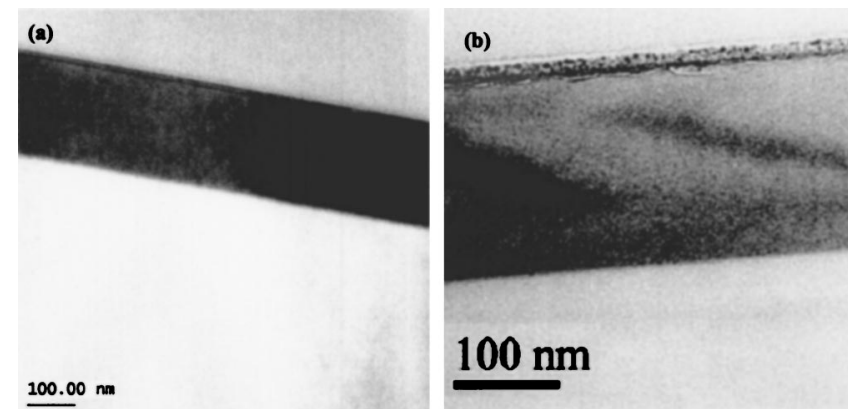

FIG. 2. XTEM images of $\mathrm{Si}_{0.79} \mathrm{Ge}_{0.21} / \mathrm{Si}$ heterostructure with a SiGe thickness of $210 \mathrm{~nm}$ : (a) CVD as grown; (b) then after plasma hydrogenation at $320-380{ }^{\circ} \mathrm{C}$ for $1.5 \mathrm{~h}$.

must be coupled with He ion implantation and relaxation in order for hydrogen to be trapped deeper within the heterostructure.

Figure 2 displays the XTEM images obtained from the $\mathrm{SiGe} / \mathrm{Si}$ structure without He implantation before [Fig. 2(a)] and after hydrogenation [Fig. 2(b)]. In the hydrogenated sample, there are no notable changes in the deeper region. However, shallow multifaceted platelets are observed in the near-surface region. As shown in Fig. 3(a), after He implantation and subsequent annealing, a band of extended defects are visible at approximately $200 \mathrm{~nm}$ below the $\mathrm{SiGe} / \mathrm{Si}$ interface. After hydrogenation [see Fig. 3(b)], long microcracks are visible at the $\mathrm{SiGe} / \mathrm{Si}$ interface running parallel to the wafer surface. At the same time, there are no indications of extended microcracks in the SiGe overlayer or in the extended defect region below the interface. The XTEM images show threading dislocation densities of $2 \times 10^{7} \mathrm{~cm}^{-2}$ or less up to the surface of the wafer from the SiGe interface.

Compared to SGOI fabrication based on the conventional ion-cutting process, hydrogen ion implantation is replaced with plasma hydrogenation in our present work. It is well known that hydrogen ion implantation introduces hydrogen-related defects, including the formation of hydrogen platelets, which evolve into hydrogen microbubbles with high internal pressure. Coalescence of these microbubbles during annealing will lead to layer splitting. Therefore, control of the hydrogen implantation energy and dose is quite important and affects the quality and efficacy of the final layer cleavage. In order to replace hydrogen ion implantation with hydrogenation, there must be a mechanism to allow hydrogen to get trapped at a desired depth to achieve $\mathrm{H}$-induced layer splitting. Therefore, $\mathrm{H}$ must be made avail-
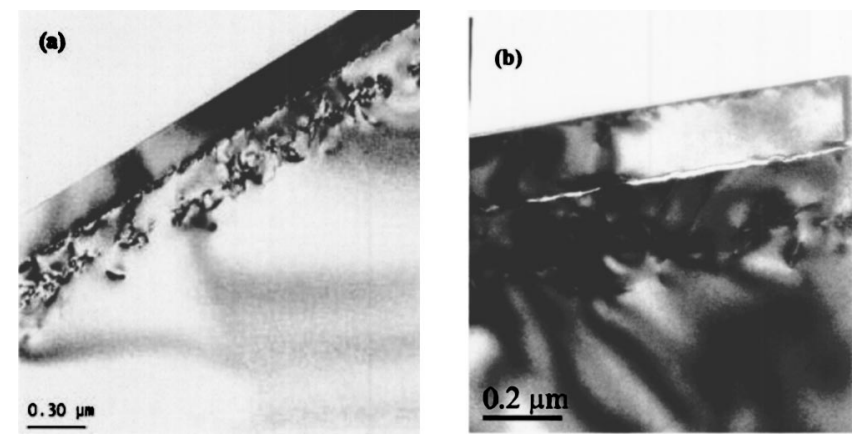

FIG. 3. XTEM images of $\mathrm{Si}_{0.79} \mathrm{Ge}_{0.21} / \mathrm{Si}$ heterostructure with a SiGe thickness of $210 \mathrm{~nm}$ : (a) After $1.5 \times 10^{16} / \mathrm{cm}^{2}, 45 \mathrm{kV} \mathrm{He}$ implantation and postannealing at $850{ }^{\circ} \mathrm{C}$ for $10 \mathrm{~min}$ in $\mathrm{Ar}$; (b) then after plasma hydrogenation at $320-380^{\circ} \mathrm{C}$ for $1.5 \mathrm{~h}$. 
able to diffuse through the SiGe layer and at the same time $\mathrm{H}$ trapping sites must be provided at a well-defined depth but nowhere else. The process described here satisfies both conditions.

In our study, the microcracking behavior in the SiGe layer during hydrogenation is found to strongly depend on the He-induced relaxation process before plasma hydrogenation. In the as-grown $\mathrm{SiGe} / \mathrm{Si}$ heterostructure without $\mathrm{He}$ relaxation, hydrogen platelets form only in the near-surface region, within several nanometers of the sample surface as seen in the XTEM image. The lack of $\mathrm{H}$ microcracks in deeper regions is attributed to the absence of $\mathrm{H}$ trapping sites. The only defective region is created at the end of range of the hydrogenation under a bias of several hundred volts. Therefore, in the case of the strained sample, $\mathrm{H}$ atoms can only pile up and form H-related defects within several nanometers of the sample surface. As a result, plasma hydrogenation, on its own, is not sufficient for layer transfer. On the other hand, the hydrogenated $\mathrm{SiGe} / \mathrm{Si}$ sample subjected to the He relaxation process exhibits a completely different microstructure that is of great relevance to layer transfer. Helium-implantation-induced relaxation has been shown to be an effective way to release the strain in a $\mathrm{SiGe/Si}$ structure with a very low threading dislocation density in the SiGe overlayer. ${ }^{10,11}$ The relaxation degree of the SiGe layer $(R)$ was measured by RBS/channeling: Angular scan along the (100) plane through [100] and [110] directions. The $R$ value for the $1.5 \times 10^{16} \mathrm{~cm}^{-2}$ sample is $55 \%$, while the asgrown sample is fully pseudomorphic $(R=0 \%)$. Appropriate $\mathrm{He}$ implantation and subsequent annealing result in the formation of high-pressure $\mathrm{He}$ bubbles below the $\mathrm{SiGe} / \mathrm{Si}$ interface as well as in the near-interface region. These bubbles can act as sources for the nucleation of dislocations. The glide (or climb) of these dislocations toward the $\mathrm{SiGe} / \mathrm{Si}$ interface causes the formation of a dense network of misfit dislocations (MD) at the interface, resulting in relaxation of the strained SiGe layer. ${ }^{12}$ The average distance between these MD is only $\sim 20 \mathrm{~nm}^{.1}$ During subsequent hydrogenation, hydrogen can diffuse into the $\mathrm{SiGe} / \mathrm{Si}$ heterostructure and get trapped at the dense MDs at the interface.

Our results suggest that the interfacial defects induced by He relaxation serve as trapping sites for hydrogen. These high-density defects located at a relatively narrow region around the $\mathrm{SiGe} / \mathrm{Si}$ interface are effective in trapping the indiffusing $\mathrm{H}$ atoms. Interacting with the interfacial defects, hydrogen atoms can accumulate at this region and cause the formation of hydrogen-related defects, including nucleation of hydrogen platelets which are the precursors of hydrogen microcracks. The simulation of ERD data shows a H concentration peak at $210 \mathrm{~nm}$ below sample surface, which is exactly the location of the $\mathrm{SiGe} / \mathrm{Si}$ interface. In accordance with the ERD data, the corresponding XTEM shown in Fig. 3(b) exhibits distinct long microcracks propagating along the interface, indicating the possibility of subsequent layer transfer. Control of the transferred depth becomes easy in the hydrogenation process resulting in a convenient method for SiGe layer transfer. Succinctly speaking, a SiGe overlayer can first be fabricated to a desired thickness on a Si substrate.
The SiGe/Si heterostructure can then be subjected to Heinduced relaxation followed by plasma hydrogenation to introduce $\mathrm{H}$ for $\mathrm{H}$-induced layer cleavage at a well-defined depth. Finally, a SGOI structure can be obtained using wafer bonding. It should be noted that because of surface damage caused by plasma hydrogenation, chemical mechanical planarization or some surface lapping may be necessary before the hydrogenated $\mathrm{SiGe} / \mathrm{Si}$ wafer is bonded to a handle wafer. The advantage of the present approach is a sharp interface for layer splitting and a very controlled way to choose the depth of splitting. Furthermore, the He implantation only damages the sample at depths deeper than the cut interface, and the hydrogenation process will cause little or no residual damage in the transferred SiGe layer.

In summary, we have investigated the feasibility of using plasma hydrogenation for relaxed SiGe layer transfer. It is found that relaxation of the as-grown strained SiGe layer is necessary to enable trapping of $\mathrm{H}$ atoms deep in the substrate. The He-induced relaxation process not only relaxes the strain in the SiGe overlayer but also provides trapping sites for hydrogen atoms at a specific depth, i.e., at the $\mathrm{SiGe} / \mathrm{Si}$ interface. Interfacial defects induced by He implantation and relaxation trap the indiffusing $\mathrm{H}$ atoms and lead to interfacial microcracks. Salient microcracks at the interface, running parallel to the wafer surface, indicate that the use of hydrogenation for the fabrication of SGOI is quite promising.

This work was jointly supported by Hong Kong Research Grants Council (RGC) Competitive Research Grants (CERG) (No. CityU 1137/03E), and City University of Hong Kong Strategic Research Grant (SRG) (No. 7001642). UCSD and ASU acknowledge the sponsorship of NSF. The work at Los Alamos National Laboratory was supported by the US DOE, Office of Basic Energy Sciences.

${ }^{1}$ Z.-Y. Cheng, M. T. Curriw, C. W. Lertz, G. Taraschi, E. A. Fitzgerald, J. L. Hoyt, and D. A. Antoniadas, IEEE Electron Device Lett. 22, 321 (2001).

${ }^{2}$ S. Fukatsu, Y. Ishilawa, T. Saito, and N. Shibata, Appl. Phys. Lett. 72, 3485 (1998).

${ }^{3}$ T. Tezuka, N. Sugiyama, and S. Takagi, Appl. Phys. Lett. 79, 1798 (2001).

${ }^{4}$ L. J. Huang, J. O. Chu, D. F. Canaperi, C. P. D'Emic, R. M. Anderson, S. J. Koester, and H.-S. Philip Wong, Appl. Phys. Lett. 781267 (2001).

${ }^{5}$ Z. Cheng, G. Taraschi, M. T. Currie, C. W. Leitz, M. L. Lee, A. Pitera, T. A. Langdo, J. L. Hoyt, D. A. Antoniadis, and E. A. Fitzgerald, J. Electron. Mater. 30, L37 (2001).

${ }^{6}$ K. Henttinen, I. Suni, and S. S. Lau, Appl. Phys. Lett. 76, 2370 (2000).

${ }^{7}$ Y. Zheng, S. S. Lau, T. Hochbauer, A. Misra, R. Verda, X.-M. He, M. Nastasi, and J. W. Mayer, J. Appl. Phys. 89, 2972 (2001).

${ }^{8}$ P. K. Chu, S. Qin, C. Chan, N. W. Cheung, and L. A. Larson, Mater. Sci. Eng., R. 17, 207 (1996).

${ }^{9}$ P. K. Chu, B. Y. Tang, Y. C. Cheng, and P. K. Ko, Rev. Sci. Instrum. 68 , 1866 (1997).

${ }^{10}$ B. Holländer, St. Lenk, S. Mantl, H. Trinkaus, D. Kirch, M. Luysberg, T. Hackbarth, H.-J. Herzog, and P. F. P. Fichtner, Nucl. Instrum. Methods Phys. Res. B 175, 357 (2001).

${ }^{11}$ D. M.Buca, B. Hollaender, S. Lenk, S. Mantl, M. Luysberg, N. Hueging, R. Loo, and M. Caymax, Mater. Res. Soc. Symp. Spring Meeting, Paper B8.12, San Francisco, Apr. 12-16, 2004.

${ }^{12}$ H. Trinkaus, B. Hollander, S. Rongen, S. Mantl, H.-J. Herzog, J. Kuchenbecker, and T. Hackbarth, Appl. Phys. Lett. 76, 3552 (2000). 